\title{
BMJ open The polypill in the primary prevention of cardiovascular disease: cost-effectiveness in the Dutch population
}

To cite: van Gils PF, Over EAB, Hamberg-van Reenen $\mathrm{HH}$, et al. The polypill in the primary prevention of cardiovascular disease: cost-effectiveness in the Dutch population. BMJ Open 2011;1:e000363. doi:10. 1136/bmjopen-2011-000363

- Prepublication history and additional material for this paper are available online. To view these files please visit the journal online (http:// bmjopen.bmj.com).

Received 14 September 2011 Accepted 17 November 2011

This final article is available for use under the terms of the Creative Commons Attribution Non-Commercial 2.0 Licence; see http://bmjopen.bmj.com

${ }^{1}$ National Institute for Public Health and the Environment, Centre for Prevention and Health Services Research, Bilthoven, the Netherlands ${ }^{2}$ National Institute for Public Health and the Environment, Centre for Public Health Forecasting, Bilthoven, the Netherlands

${ }^{3}$ Julius Centre for Health Sciences and Primary Care, University Medical Centre Utrecht, Utrecht, the Netherlands

${ }^{4}$ Department of Health Sciences, EMGO Institute for Health and Care Research, VU University, Amsterdam, the Netherlands

Correspondence to Paul F van Gils; paul.van.gils@rivm.nl

\section{ABSTRACT}

Objectives: The aim of the present study was to estimate the cost-effectiveness of the polypill in the primary prevention of cardiovascular disease.

Design: A health economic modelling study.

Setting: Primary healthcare in the Netherlands.

Participants: Simulated individuals from the general Dutch population, aged $45-75$ years.

Interventions: Opportunistic screening followed by prescription of the polypill to eligible individuals. Eligibility was defined as having a minimum 10-year risk of cardiovascular death as assessed with the Systematic Coronary Risk Evaluation function of alternatively $5 \%, 7.5 \%$ or $10 \%$. Different versions of the polypill were considered, depending on composition: (1) the Indian polycap, with three different types of blood pressure-lowering drugs, a statin and aspirin; (2) as (1) but without aspirin and (3) as (2) but with a double statin dose. In addition, a scenario of (targeted) separate antihypertensive and/ or statin medication was simulated.

Primary outcome measures: Cases of acute myocardial infarction or stroke prevented, qualityadjusted life years (QALYs) gained and the costs per QALY gained. All interventions were compared with usual care.

Results: All scenarios were cost-effective with an incremental cost-effectiveness ratio between $€ 7900$ and 12300 per QALY compared with usual care. Most health gains were achieved with the polypill without aspirin and containing a double dose of statins. With a 10-year risk of $7.5 \%$ as the threshold, this pill would prevent approximately $3.5 \%$ of all cardiovascular events.

Conclusions: Opportunistic screening based on global cardiovascular risk assessment followed by polypill prescription to those with increased risk offers a costeffective strategy. Most health gain is achieved by the polypill without aspirin and a double statin dose.

\section{INTRODUCTION}

In a by now famous article in the British Medical Journal in 2003, Wald and Law ${ }^{1}$ suggested that a 'polypill' could be of great

\section{ARTICLE SUMMARY}

Article focus

- Cardiovascular diseases continue to be still a major partly preventable, cause of illness and death.

- A polypill that lowers by targeting several risk factors simultaneously is in line with the concept that the aim in primary prevention should be to bring down 'global' cardiovascular risk.

- The aim of this study was to estimate the potential cost-effectiveness of polypill prescription after opportunistic screening.

Key messages

- The results of this study suggest that opportunistic screening and offering a polypill to people with a minimum 10-year risk of cardiovascular mortality of alternatively $5 \%, 7.5 \%$ or $10 \%$ is a cost-effective strategy.

- A polypill without aspirin but with a double dose of simvastatin leads to most health gains at all risk thresholds considered. At a 10-year risk of cardiovascular death of $\geq 7.5 \%$, such a strategy would lead to an estimated decrease in the incidence of myocardial infarction and stroke of about $3.5 \%$, at a cost of $€ 8900$ per qualityadjusted life year.

- Opportunistic screening of the population of $\geq 40$ years to select individuals with a mild to moderately increased risk for cardiovascular diseases, followed by polypill prescription would prevent approximately $3.5 \%$ of all cardiovascular events.

benefit in the prevention of cardiovascular disease (CVD). As originally proposed, such a pill would consist of a combination of drugs with proven efficacy and safety in reducing cardiovascular risk, in particular three different types of blood pressure-lowering drugs (a $\beta$ blocker, an antidiuretic and an ACE inhibitor), one lipid-lowering drug, an antiplatelet agent (aspirin) and folic acid to reduce serum homocysteine. In combination, lower dosages could be used resulting in 


\section{ARTICLE SUMMARY}

Strengths and limitations of this study

- Strong point of the study is that different compositions of the polypill have been modelled. Also, realistic estimates for adherence and compliance have been used.

- As only preliminary results of a phase II clinical trial on efficacy of the polypill were available, we had to apply mathematical modelling to estimate cost-effectiveness. This provides insight into the range of health benefits that can be expected. Pending results with regard to established clinical endpoints from largescale phase III trials, the results of this study should not be taken as a precise estimate of the cost-effectiveness of the polypill.

greater efficacy than single medication with a more favourable safety profile than higher dosages of individual drugs.

CVDs are still a major cause of illness and death. For example, estimates show that in the year $2006>80$ million people in the USA had one or more forms of $\mathrm{CVD}^{2}$ In 2009, CVD was responsible for $29 \%$ of all deaths in the Netherlands, taking second place after cancer $(32 \%)$ as the most important cause of death. ${ }^{3}$ Ischaemic heart disease and stroke together were responsible for $27 \%$ of all hospitalisations. ${ }^{4}$

As CVD is the result of a gradual process of atherosclerosis building up over many years, the most rational strategy is stopping, or at least slowing down, the progress of plaque formation. For those whose risk factor levels put them at increased risk, life style measures or medication are available for primary prevention but identifying who might benefit and what measures are most appropriate is subject of much discussion. ${ }^{5-8}$ The recognition that atherosclerotic CVD is the product of multiple interacting risk factors has in the past decades led to new approaches in prevention. In particular, the concepts of global risk, being the aggregate risk of all risk factors together and total CVD risk assessment have emerged as an important inspiration for developing guidelines on cardiovascular risk management. ${ }^{9}$ Examples of methods of global risk assessment are the well-known Framingham risk score and the Systematic Coronary Risk Evaluation (SCORE), the latter based on a pooled data set of 12 European cohort studies. ${ }^{10} \mathrm{~A}$ consequence of the global risk approach is that the focus of intervention shifts from treatment of individual risk factors to placing emphasis on reducing total CVD risk, irrespective by what means. Thus, the idea of a polypill, that lowers risk by targeting more than one risk factor simultaneously, seems perfectly tailored to this strategy. ${ }^{11}$ In addition, it provides a 'one stop shop' when someone could benefit from more than one type of medication.

Up to the present, no evidence for the effectiveness of such a polypill exists. Yet, randomised clinical trials with several versions of a polypill have been started. The Indian Polycap Study was a phase II, randomised doubleblind clinical trial designed to test the effects of a version of the polypill on intermediate measures for the devel- opment of CVD, in particular blood pressure, cholesterol, heart rate and urinary dehydrotromboxane B2. ${ }^{12}$ The polypill used in this randomised controlled trail differed from the one suggested by Wald and Law by omitting folic acid, as the supposed effects of folic acid on serum homocysteine have not been confirmed. ${ }^{13}$ Medication was only given for a period of 12 weeks in the Polycap Study.

Even though there is still no evidence regarding the efficacy of a polypill on hard endpoints (acute myocardial infarction, stroke), the extensively validated relation between blood pressure and cholesterol level on the one hand and disease risk on the other allows a first exploration of the range of costs and benefits that might be expected from the polypill in the prevention of CVDs.

The aim of this study was to estimate the potential costeffectiveness of the polypill in the primary prevention of myocardial infarction and ischaemic stroke. In order to explore this issue, a scenario of opportunistic screening in primary care was taken as point of departure. Patients were eligible for prescription of the polypill starting from a $5 \%$ risk up to $10 \%$ risk of cardiovascular death in 10 years, based on their SCORE function. ${ }^{14}$

\section{METHODS}

We conducted a simulation study using a computer model (RIVM Chronic Disease Model (CDM)) developed at our institute. ${ }^{15} 16$ Point of departure for the simulations was a scenario, in which the polypill is offered to eligible patients identified during routine visits to their general practitioner (GP) ('opportunistic screening'). The GP takes the initiative suggesting to patients to determine their 10-year risk for cardiovascular mortality. Those aged $40-75$ years without known previous CVD are eligible for the screening. Starting from risk levels of $\geq 5 \%$, people will be offered lifelong preventive medication. Cardiovascular mortality risk is assessed using the SCORE risk function developed and recommended by the European Society of Cardiology and endorsed in the Netherlands by professional and patients' organisations. ${ }^{17}$ The score function is calculated using age, sex, blood pressure, cholesterol and smoking status as input.

The current Dutch guideline for primary cardiovascular prevention, which was introduced in 2006, recommends the SCORE risk charts to determine treatment recommendations. For this purpose, a version of the SCORE was developed adapted to Dutch risk factor and mortality data. ${ }^{14}$ It is the algorithm for this version that we used in our analyses.

According to the Dutch guideline, for individuals with a 10-year risk of cardiovascular death of $\geq 10 \%$ targeted drug therapy is recommended: antihypertensive treatment when systolic blood pressure (SBP) $\geq 140$ and statins when low-density lipoprotein (LDL) cholesterol $>2.5 \mathrm{mmol} / \mathrm{l}$. When risk exceeds $5 \%$, life style counselling should be considered. Aspirin is recommended for 
secondary prevention only. ${ }^{18}$ Following the rationale that arguments for the polypill are based on the expectancy of a more favourable benefit versus safety profile, we assumed that, in a situation where a polypill would be available, it would be considered to lower the threshold for prescribing preventive medication. On the other hand, it seems unlikely that preventive medication would be considered for everyone, even those with risks below $5 \%$. Therefore, in order to assess the effect of different choices for the threshold, we performed analyses for different cut-points: $5 \%, 7.5 \%$ and $10 \%$, the threshold for drug treatment of the present guideline.

\section{The RIVM chronic disease model}

The CDM is a computer simulation model designed to be able to simulate the evolution of several chronic diseases in relation to risk factor levels in the Dutch population. It includes the most common chronic diseases, among which chronic obstructive pulmonary disease, diabetes mellitus type 2, myocardial infarction and stroke, and in addition a number of life style-related risk factors, such as smoking, blood pressure and cholesterol. It may be best characterised as a Markovtype multistate-transition model. ${ }^{15}{ }^{16}$ The model describes the development over time of demography, risk factor prevalence, disease incidence and mortality, in 1-year time steps. As input, it takes the age and sex composition of the current Dutch population as well as its distribution according to risk factor levels. It further requires specification of three types of transition probabilities (the probability of going from one state to another in 1-year time): between risk factor levels, between disease states (ie, disease incidence), for each disease in the model. Disease incidence and mortality depend on risk factor levels and the presence of other diseases via relative risks (RRs). Estimates of RRs were derived from literature, whereas incidence, prevalence, transition rates and mortality rates in the model apply to the Dutch population. In addition, each disease is associated with average yearly, per patient, costs and with disability weights. All data are age and sex specific. The model further allows specifying alternative 'scenarios', by adjusting the input parameters and comparing the results obtained with other scenarios with the 'reference scenario (see below)'. Healthcare costs were based on costs-of-illness studies in the Netherlands, ${ }^{1920}$ and the healthcare outcome measure 'quality-adjusted life year (QALY)' was computed using the Global and Dutch burden of disease studies. ${ }^{21-24}$

\section{Scenarios}

Several scenarios were defined based on (1) different cutoff levels for 10-year risk: $5 \%, 7.5 \%$ and $10 \%$ and (2) different compositions of the polypill. These scenarios were compared with the reference scenario of care as usual and with each other. Usual care is represented in our model in the reference scenario by the proportion of individuals currently being treated with statins and/or antihypertensive agents, based on data from the Doetin- chem Cohort Study (details about this study follow later) ${ }^{25}$ It is assumed that individuals already being treated with drugs will not switch to the polypill. We further assume that people identified as being at risk by opportunistic screening would otherwise not receive preventive medication. In other words, the polypill was prescribed only to unexposed individuals who did not already use one of the drugs included in the polypill. The different scenarios explored using the CDM model are: (1) The reference scenario represents the expected evolution of the health status and risk factor distribution of the Dutch population as simulated by the model using the basic input parameters that represent the relevant characteristics of the current Dutch population (current practice).

(2) The polypill scenarios simulate the situation in which all eligible individuals, not yet treated with statins or antihypertensive agents, and selected by 'opportunistic screening', are offered lifelong medication. Besides the original Indian 'Polycap' composition, we also considered different versions of the polypill without aspirin that would avoid the bleeding risks associated with antiplatelet agents. Thus, the following alternative compositions of polypills were considered:

(2A) The 'Indian polycap', consisting of $20 \mathrm{mg}$ simvastatin, $12.5 \mathrm{mg}$ thiazide, $5 \mathrm{mg}$ ramipril, $50 \mathrm{mg}$ atenolol and $100 \mathrm{mg}$ aspirin.

(2B) As (2A) but without aspirin.

(2C) As (2B) but with $40 \mathrm{mg}$ simvastatin (double dose statins, ie, Dutch standard dose when given as monotherapy).

Finally, an alternative scenario was defined (scenario 3: 'separate medication') in which screened individuals eligible for the polypill will not be offered the polypill, but rather medication tailored to the underlying risk factor: a statin in case of hypercholesterolaemia, an antihypertensive in case of hypertension, both or none (ie, the risk score is increased, but blood pressure and hypertension are below the respective cut-points).

Basically, the analyses compare the scenarios in which medication is offered in primary care to all eligible individuals in the age group 40-75 years with the scenario in which usual care is continued. The comparison thus is between a hypothetical population with one of the interventions described above and one without, where in all other respects the populations are equal at baseline and represent the current Dutch population. The model is 'run' until all have died and no 'inflow' of younger individuals is taken into account.

Below, we describe how we derived values for the relevant parameters for each scenario.

Estimation of the number of eligible individuals and of the proportion who would be treated

In order to estimate the numbers of individuals who would receive the polypill, the following steps were taken (figure 1).

First, the proportion of the population aged $40-75$ years without a history of CVD and not yet treated 
with statins or antihypertensives was estimated. To this end, we applied the SCORE algorithm to the most recent data of the Doetinchem Cohort Study. The Doetinchem Cohort Study is a prospective study of $>5000$ inhabitants of the city of Doetinchem and surroundings who were included in the years 1987-1991. Participants were aged 20-65 years at inclusion and have been followed for $>20$ years now. So far, four rounds of data collection have been completed, roughly at 5-year intervals. We used the data of round 4, collected during the years 2003-2007. Among the data collected, all variables necessary to calculate the SCORE are included (age, sex, SBP, LDL cholesterol, smoking status, treatment status of statins and antihypertensive). The Doetinchem cohort has been described elsewhere. ${ }^{25}$ The cohort represents the best available source for the Netherlands to determine the current population distribution of risk factors.

Next, we needed to estimate how many people would be reached by opportunistic screening.

Data taken from Statistics Netherlands show that approximately $75 \%$ of the Dutch population visit their GP at least once every year. ${ }^{26}$ We assumed that this figure also applies to our target population. We further assumed that the GP offers a screening consultation to all in the target population (those aged $40-75$ years) in the year of the intervention and that $50 \%$ of the invited population consent. Risk assessment consists of one consultation with the GP, who explains the procedure, measures blood pressure and draws blood for a labora- tory test of blood cholesterol. The patient is then invited for a second consultation to calculate the SCORE and discuss the consequences.

We finally assumed that of those who are offered the polypill (SCORE $\geq 5 \%, 7.5 \%$ or $10 \%$ ) or a separate statin/antihypertensive, $85 \%$ will decide to take the pill for at least 1 year ${ }^{12}$ and that compliance rates would stabilise at $50 \%$ after 5 years. A flow chart of the process of screening and selecting patients is shown below: for the separate medication scenario (scenario 3), we assumed that adherence (willingness to start with the therapy) to the antihypertensive was $90 \%$ and adherence to the statin was $60 \%,{ }^{27}$ which fraction was multiplied by the before-mentioned compliance rate to achieve overall compliance (willingness to continue the therapy).

\section{Effects}

A crucial parameter in implementing the polypill scenarios is the measure of its efficacy, in particular the RR reduction: the RR for acute myocardial infarction or stroke after taking the medication compared with the RR before taking it (or in a control (placebo) group). Unfortunately, as mentioned above, so far there are no data on the effects of the polypill on cardiovascular events. Instead, we will have to base our estimate on the effects on 'intermediate' measures, that is, blood pressure and cholesterol. In particular, we use the outcomes of the Indian Polycap Study. ${ }^{12}$ As mentioned above, the Indian polypill consist of three blood pressure-lowering drugs: hydrochlorthiazide $12.5 \mathrm{mg}$ (a diuretic), atenolol
Figure 1 Flow chart of participation.

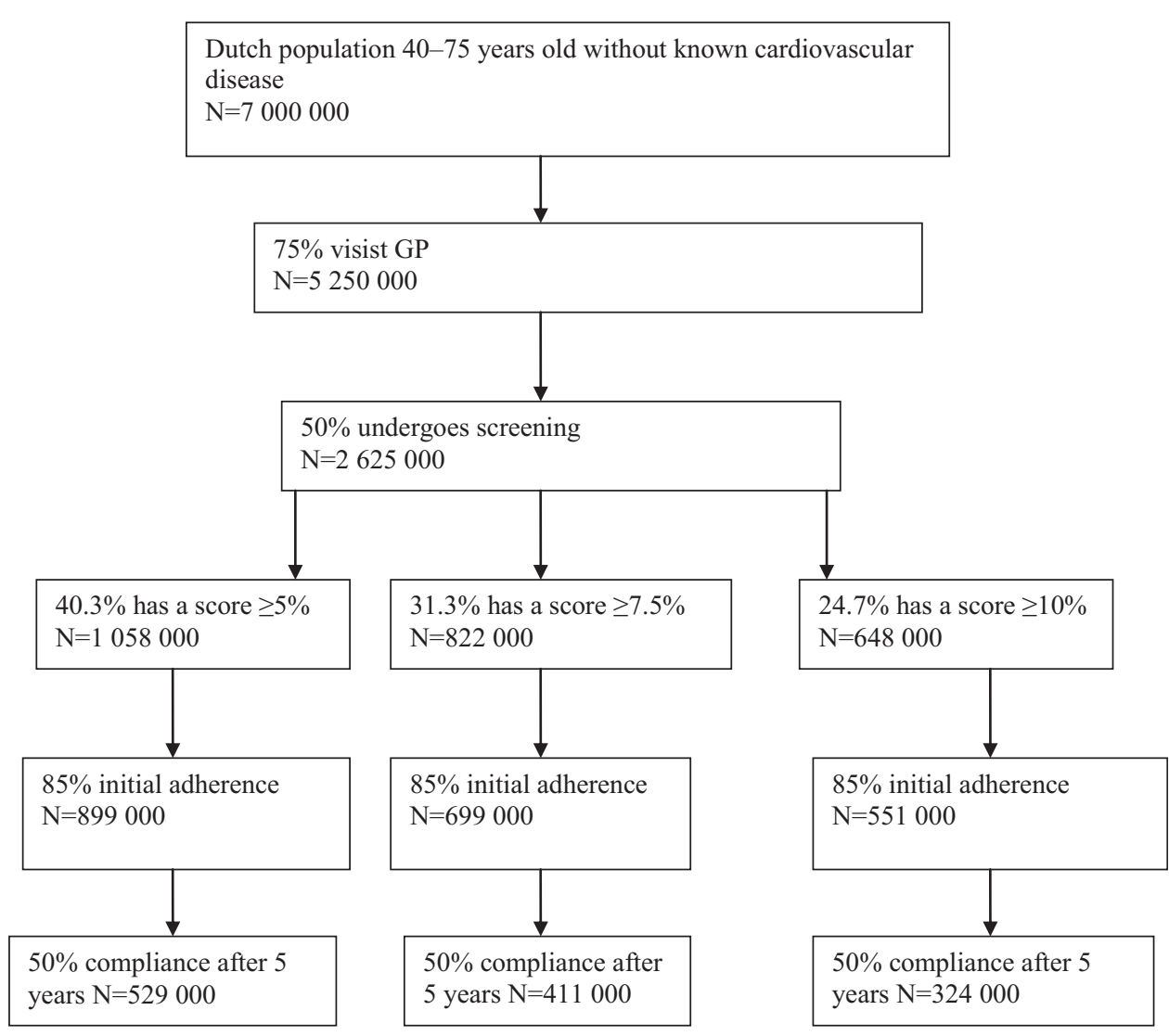


$50 \mathrm{mg}$ (a $\beta$ blocker) and ramipril $5 \mathrm{mg}$ (an ACE inhibitor); a lipid-lowering drug (simvastatin $20 \mathrm{mg}$ ) and an antiplatelet (aspirin $100 \mathrm{mg}$ ). The effect of the polypill on blood pressure was a lowering of the diastolic blood pressure with $5.7 \mathrm{~mm} \mathrm{Hg}$ (95\% CI 4.7 to 6.4) and of the SBP with $7.4 \mathrm{~mm} \mathrm{Hg}$ (95\% CI 6.1 to 8.1). The LDL cholesterol was reduced by $0.80 \mathrm{mmol} / 1(95 \% \mathrm{CI} 0.62$ to $0.78) .{ }^{12}$

These effects on blood pressure and cholesterol are substantially lower than what Law and Wald predicted. Thus, the RR reductions suggested in their article and in the accompanying meta-analysis of combination treatment with blood pressure-lowering drugs ${ }^{28}$ could not be relied upon for our purposes. Instead, we took as a basis the reductions in blood pressure and cholesterol observed in the Polycap Study and translated these into corresponding RR reductions using meta-analyses providing estimates of these relations.

\section{Blood pressure lowering}

For blood pressure, we used a recent meta-analysis of the Blood Pressure Lowering Treatment Trialists' Collaboration. ${ }^{29}$ Although the published article only reported results for 'major cardiovascular events' as outcome, supplementary analyses for stroke and coronary heart disease separately were obtained from the authors. For each $5 \mathrm{~mm} \mathrm{Hg}$ reduction in SBP, the following RRs were found for stroke, 0.83 (95\% CI 0.74 to 0.94 ) for those under 65 years of age and of 0.91 (95\% CI 0.84 to 0.99 ) for those aged 65 years or older; for coronary heart disease, 0.87 (95\% CI 0.80 to 0.95 ) and 0.90 (95\% CI 0.84 to 0.98 ), respectively, and for total mortality, 0.92 (95\% CI 0.85 to 0.99 ) and 0.96 (95\% CI 0.91 to 1.02), respectively. The relation between blood pressure reduction achieved and risk reduction was found to be $\log$ linear. Moreover, the authors compared various drug classes and concluded that there were no differences on the effects of lowering blood pressure according to drug class. Also when combinations of drugs are given, the effect on risk has been found to depend only on the reduction in blood pressure achieved. ${ }^{28}$

Assuming the findings of this meta-analysis, we calculated the RRs corresponding to a $7.4 \mathrm{~mm} \mathrm{Hg}$ reduction by raising the RRs to the power $(7.4 / 5)$. This resulted in the following RRs: for stroke, 0.76 (95\% CI 0.91 to 0.64 ) for those under 65 years of age and 0.87 (95\% CI 0.98 to 0.77 ) for those aged 65 years or older; for coronary heart disease, 0.82 (95\% CI 0.92 to 0.72 ) and 0.86 (95\% CI 0.96 to 0.77 ) respectively, and for total mortality, 0.88 (95\% CI 0.99 to 0.79 ) and 0.94 (95\% CI 1.03 to 0.87 ), respectively.

For separate treatment, we took treatment with a diuretic or $\beta$ blocker as standard. From a meta-analysis by the Blood Pressure Lowering Treatment Trialists'Collaboration, ${ }^{30}$ which compared various bloodlowering agents both with each other and to placebo, we inferred that on average a diuretic results in a reduction of $7.2 \mathrm{~mm} \mathrm{Hg}$. As this is almost the same as the reduction achieved by the polypill, we used the same RR reduction values.

\section{Cholesterol lowering}

For statins, we used a recent meta-analysis by the Cochrane Collaboration on statins for the primary prevention of CVD. ${ }^{31}$ The mean difference in LDL cholesterol between treatment groups and controls was $-0.92(95 \% \mathrm{CI}-1.10$ to $-0.0 .74)$, corresponding to RRs of 0.72 (95\% CI 0.65 to 0.79 ) for coronary events, 0.78 (95\% CI 0.65 to 0.94$)$ for stroke and 0.84 (95\% CI 0.73 to 0.96 ) for total mortality. As the reduction found in the Polycap Study was 0.80 , we adjusted the RRs reported for the meta-analysis by raising them to the power $0.80 / 0.92$. This is based on the assumption that the RR has a loglinear relation with the reduction in cholesterol level (each millimoles per litre reduction reduces the risk by the same factor), for which there is much evidence. ${ }^{32}$ After this adjustment, we found the following RRs: for coronary heart disease events, it was 0.75 (95\% CI 0.69 to $0.82)$; for stroke, it was 0.81 (95\% CI 0.69 to 0.95$)$ and for total mortality, it was 0.86 (95\% CI 0.76 to 0.97 ). Again, assuming the log linearity between level reduction and RRs, we calculated for the double dose the following RRs: for coronary heart disease events, it was 0.52 (95\% CI 0.42 to 0.62$)$; for stroke, it was $0.61(95 \%$ CI 0.42 to 0.88$)$ and for total mortality, it was $0.71(95 \%$ CI 0.53 to 0.92 ).

In the literature, no difference was found in the number of adverse events or in the number of individuals who developed cancer or myalgia. ${ }^{31} 3334$

\section{Antiplatelet effects}

A recent meta-analysis of aspirin in the primary prevention of vascular disease ${ }^{35}$ found the following RRs for the treatment group versus the control group: any major coronary event 0.82 (95\% CI 0.75 to 0.90 ) and no significant net effect on stroke (decrease in ischaemic strokes annulled by an increase in haemorrhagic strokes).

Table 1 gives an overview of the risk reductions used due to simvastatin, the blood pressure-lowering agents and aspirin. RRs of those using medication versus those without medication as used in the model are expressed separately for the different types of medication. Effects are assumed to be independent. To calculate the aggregate effect of a particular combination RRs are multiplied.

\section{Costs}

Costs were determined from the perspective of the healthcare payer and according to the national guideline for costing research in health economic analysis. ${ }^{36}$ Direct medical costs associated with diseases per patient per year were included in the CDM. ${ }^{19}{ }^{20}$ Costs due to all medical treatment in life years gained (indirect medical cost) are automatically included in the model. 
Table 1 RRs versus no medication $(95 \% \mathrm{Cl})$

\begin{tabular}{llllll}
\hline $\mathbf{R R}$ & Statin $\mathbf{2 0} \mathbf{~ m g}$ & Statin $\mathbf{4 0} \mathbf{~ m g}$ & BPL in PP & BPL separate & Aspirin \\
\hline Total mortality & $0.86(0.76$ to 0.97$)$ & $0.71(0.53$ to 0.92$)$ & $0.91(0.83$ to 1.00$)$ & $0.91(0.83$ to 1.00$)$ & 1 \\
CVA & $0.81(0.69$ to 0.95$)$ & $0.61(0.42$ to 0.88$)$ & $0.81(0.70$ to 0.94$)$ & $0.81(0.70$ to 0.94$)$ & 1 \\
AMI & $0.75(0.69$ to 0.82$)$ & $0.52(0.42$ to 0.62$)$ & $0.84(0.74$ to 0.94$)$ & $0.84(0.74$ to 0.94$)$ & $0.82(0.75$ to 0.90$)$ \\
\hline
\end{tabular}

AMI, acute myocardial infarction; BPL, blood pressure-lowering drug; CVA, cerebrovascular accident; PP, polypill.

\section{Costs for screening and drug use}

Unit costs, including costs for GP visits, laboratory testing, medication and drug delivery, are presented in table 2.

Costs during the first year consist of two GP visits, one laboratory test and if indicated the costs of medication and drug delivery.

During the second and subsequent years, the costs consist of one GP visit (control visit), one laboratory test and the costs of drug delivery.

As currently the polypill is not yet on the market, a price had to be estimated based on its 'ingredients'. We took as our reference the costs per milligrams of statins, $\beta$ blockers, ACE inhibitors and aspirin prescribed as generics in the Netherlands, and we assumed that the price of a pill would be the sum of the prices of its components. ${ }^{37}$ Thus, the Polycap pill (scenario 1) would cost $€ 89.75$ per year, including fees for prescription and drug delivery.
Costs and effects associated with adverse events

The frequency of adverse effects of the use of statins and antihypertensive agents has consistently been reported to be very low. We assumed that the costs and effects due to these agents are captured by taking into account nonadherence and stopping taking the pill. The adverse effects of aspirin, however, are known to be more severe. In particular, the risks of major bleedings should be taking into account. The increased risk of hemorrhagic stroke is already incorporated in our estimate of the RR for stroke (see above). The costs and (negative) effects of gastrointestinal bleedings caused by the use of aspirin were added to the model in the following manner. The incidence rate of gastrointestinal bleedings was estimated to $8.5 /$ year/1000 patients. ${ }^{38}$ The loss of utility caused by gastrointestinal bleedings was estimated to be $0.06 .{ }^{39}$ The costs of gastrointestinal bleeding were estimated at $€ 3425$, according to the Dutch DiagnosisRelated Group tariff (http://www.nza.nl).

Table 2 Intervention costs

\begin{tabular}{|c|c|c|c|}
\hline Item & Unit & $\begin{array}{l}\text { Costs per } \\
\text { unit/quantity in PP }\end{array}$ & $\begin{array}{l}\text { Costs per } \\
\text { person per year }\end{array}$ \\
\hline GP visit* & \multirow[t]{3}{*}{$\begin{array}{l}\text { Standard } \\
\text { consultation }\end{array}$} & $€ 29$ & $\begin{array}{l}€ 58 \text { (first year) } \\
€ 29 \text { (subsequent years) }\end{array}$ \\
\hline Blood drawing & & \multicolumn{2}{|l|}{ Included } \\
\hline Laboratory & & $€ 1.70$ & $€ 1.70$ \\
\hline \multicolumn{4}{|l|}{ Drug costs $†$} \\
\hline Simvastatin $20 \mathrm{mg}$ dd & 1 year & $€ 6.69$ & $€ 6.69$ \\
\hline Simvastatin $40 \mathrm{mg}$ & 1 year & $€ 13.39$ & $€ 13.39$ \\
\hline Ramipril $2.5 \mathrm{mg}$ & 1 year & $€ 22.48$ & $€ 22.48$ \\
\hline Atenolol $50 \mathrm{mg}$ & 1 year & $€ 22.48$ & $€ 22.48$ \\
\hline Thiazide $12.5 \mathrm{mg}$ & 1 year & $€ 3.47$ & $€ 3.47$ \\
\hline Aspirin $100 \mathrm{mg}$ & 1 year & $€ 3.70$ & $€ 3.70$ \\
\hline \multirow[t]{2}{*}{ Drug delivery costs $\ddagger$} & First delivery & $€ 5.74$ & \\
\hline & Per 3 months & $€ 5.74$ & $\begin{array}{l}€ 28.70 \text { (first year) } \\
€ 22.96 \text { (subsequent years) }\end{array}$ \\
\hline Repeat prescription $\ddagger$ & & Included in basic tariffs & \\
\hline Gastrointestinal bleeding (adverse event) $\ddagger$ & & $€ 3425$ & $€ 3425$ \\
\hline \multicolumn{4}{|c|}{$\begin{array}{l}\text { Costs in the first year consist of two GP visits, one laboratory test, four times drug delivery and an additional charge for first drug delivery. Costs } \\
\text { in subsequent years: one GP visit plus one laboratory test plus four times drug delivery costs. } \\
\text { *Fees in the Netherlands are determined by the national regulator of healthcare tariffs: Nederlandse Zorgautoriteit (National Health Authority). In } \\
\text { addition to costs per visit, GPs are paid for each patient registered in their practice on a yearly basis (http://www.nza.nl). Consulted on } 16 \text { June } \\
2011 . \\
\text { †Drug costs are based on the costs as calculated and publicised by the College for Health Insurance, which determines the prices for } \\
\text { reimbursement (pharmacotherapeutic compass: http//www.cvz.nl/kompas). } \\
\neq \text { According to maximum fees set for the year } 2011 \text { by National Health Authority (nza, 'tariefbeschikking' nr. TB/CU-5000-01, nr. } 34, \text { http://www. } \\
\text { nza.nl). }\end{array}$} \\
\hline
\end{tabular}


Total costs

Total costs were calculated by multiplying unit costs with volumes. Volumes were derived by determining the 'numbers of units per patient' and the numbers of patients at each stage in the process: first screening, then start therapy, first year and finally all subsequent years of the simulation.

\section{Cost-effectiveness}

The main endpoint of this study was the cost-effectiveness ratio expressed as the ratio of the difference in costs and the difference in QALYs when comparing the alternative scenarios with the reference scenario (Cost/QALY).

As the rationale for prescribing the polypill is to prevent CVD, we also determined the numbers of myocardial infarctions and strokes prevented in the different scenarios. This was done by calculating the differences in the cumulative incidences between scenarios. Finally, these figures were used to estimate the numbers of patients that would have to be treated (number needed to treat) to prevent one myocardial infarction or one stroke. Taking into account time preferences, future costs and effects were discounted according to the Dutch guideline, with a discount rate of $4 \%$ for costs and $1.5 \%$ for effects. ${ }^{36}$ The chosen time horizon was a lifetime horizon.

\section{Probabilistic sensitivity analyses}

As several important assumptions had to be made in modelling the cost-effectiveness of the polypill, we explored the range of likely outcomes with a probabilistic multivariate sensitivity analysis. The key variables with known uncertainty were screening acceptance, adherence to medication, RRs for developing stroke and myocardial infarction, and the RR for all-cause mortality. Screening acceptance was taken to be distributed as a $\beta$ distribution $(\alpha=5, \beta=5)$ so that the average acceptance was 0.50 , with a $95 \%$ CI of (0.21 to 0.79$)$. First year's adherence was taken from a $\beta$ distribution $(\alpha=42.5, \beta=7.5)$ so that the average first year's adherence was 0.85 , with a $95 \%$ CI of (0.74 to 0.93$)$. The RRs were randomly taken from $\beta$ distributions with characteristics as mentioned in table 1. We performed 350 simulations in total.
Another key parameter in the model was the price of the polypill. Because the polypill is not commercially available (yet), its price is unknown. As the best estimate, we used the sum of the costs of the separate elements of the polypill. However, if pill prices will be largely determined by production costs, it is likely that the pill will be considerably cheaper than the sum of the costs of its components. On the other hand, if, for instance the added value to the consumer of having to take one pill only will be priced in, it cannot be ruled out that the price will be higher. For lack of an informed estimate of price ranges, we explored an array of possible values in order to compare with the costs of separate medication. We performed also analyses with different discount rates.

\section{RESULTS}

\section{Descriptives}

Table 3 shows the proportion of individuals eligible for medication based on a 10-year risk of cardiovascular mortality threshold of $5 \%, 7.5 \%$ or $10 \%$. For example, with a threshold of $7.5 \%$, of all persons between 40 and 75 years, $>31 \%$ was eligible for medication. The first half of the table concerns those eligible for the polypill and the second half those eligible for separate medication, based on having a SCORE risk of $\geq 7.5 \%$ together with hypertension and/or hypercholesterolaemia ('separate medication scenario', scenario 3).

\section{Effectiveness}

Table 4 shows that by using the polypill as described for scenario 2C, the number of cases of acute myocardial infarction or stroke prevented, almost 30, respectively 47 thousand for a threshold of $7.5 \%$ (5\% and $10 \%$ not shown), was more than for the other polypill scenarios. It should be noted that the total health gain in the separate medication scenario (scenario 3 ) is more than $1 / 2$ of the total health gain of scenario $2 \mathrm{C}$.

\section{Cost-effectiveness}

Table 5 shows the incremental cost-effectiveness ratios (ICERs) for all scenarios. The ratios do not differ very much between the three SCORE cut-off values considered and are all well within accepted ICER thresholds.

Table 3 Individuals ${ }^{*}$ eligible for the polypill and separate medication (\% of total population)

\begin{tabular}{|c|c|c|c|c|c|c|c|c|c|c|c|c|c|c|c|c|c|c|}
\hline \multirow[b]{3}{*}{ Risk threshold } & \multicolumn{9}{|c|}{ Polypill } & \multicolumn{9}{|c|}{ Separate medication } \\
\hline & \multicolumn{3}{|l|}{ Men } & \multicolumn{3}{|c|}{ Women } & \multicolumn{3}{|c|}{ Total } & \multicolumn{3}{|c|}{ Men } & \multicolumn{3}{|c|}{ Women } & \multicolumn{3}{|c|}{ Total } \\
\hline & $5 \%$ & $7.5 \%$ & $10 \%$ & $5 \%$ & $7.5 \%$ & $10 \%$ & $5 \%$ & $7.5 \%$ & $10 \%$ & $5 \%$ & $7.5 \%$ & $10 \%$ & $5 \%$ & $7.5 \%$ & $10 \%$ & $5 \%$ & $7.5 \%$ & $10 \%$ \\
\hline \multicolumn{19}{|l|}{ Age, years } \\
\hline $40-49$ & 9.1 & 2.2 & 0.4 & 0.0 & 0.0 & 0.0 & 4.0 & 1.0 & 0.2 & 8.7 & 2.1 & 0.4 & 0.0 & 0.0 & 0.0 & 3.8 & 0.9 & 0.2 \\
\hline $50-59$ & 61.3 & 38.3 & 22.7 & 6.0 & 1.7 & 0.5 & 32.1 & 19.0 & 11.0 & 50.7 & 32.8 & 20.1 & 5.8 & 1.7 & 0.5 & 27.2 & 16.5 & 9.8 \\
\hline $60-69$ & 98.8 & 93.4 & 83.5 & 72.1 & 47.5 & 30.0 & 85.7 & 70.9 & 57.2 & 74.9 & 73.3 & 68.1 & 61.3 & 41.2 & 26.5 & 68.2 & 57.6 & 47.7 \\
\hline $70-75$ & 98.9 & 98.9 & 98.4 & 100.0 & 97.0 & 87.0 & 99.4 & 98.0 & 92.9 & 72.7 & 72.7 & 72.7 & 76.3 & 75.8 & 71.1 & 74.5 & 74.2 & 71.9 \\
\hline $\begin{array}{l}\text { All ages } \\
(40-75)\end{array}$ & 57.4 & 46.2 & 37.7 & 25.0 & 18.0 & 13.1 & 40.3 & 31.3 & 24.7 & 46.2 & 37.8 & 31.5 & 21.9 & 16.0 & 11.9 & 33.4 & 26.3 & 21.2 \\
\hline
\end{tabular}


Table 4 Number of cases prevented over time by the polypill intervention at a 10 -year risk of $7.5 \%$

\begin{tabular}{|c|c|c|c|c|c|c|}
\hline Scenario (PP intervention) & \multicolumn{3}{|l|}{ AMI } & \multicolumn{3}{|l|}{ Stroke } \\
\hline Expected ${ }^{*}$ & $807 \mathrm{k}$ & & & $1374 \mathrm{k}$ & & \\
\hline & Cases prevented & & & Cases prevented & & \\
\hline Polypill scenario $2 \mathrm{~A}$ & $23.8(8.3-41.6) \mathrm{k}$ & $2.89(1.02-5.06)$ & 31 & $36.1(12.3-72.9) \mathrm{k}$ & $2.57(0.86-5.12)$ & 20 \\
\hline Polypill scenario 2B & $22.5(8.3-38.8) \mathrm{k}$ & $2.73(1.00-4.70)$ & 33 & $36.2(12.3-72.9) \mathrm{k}$ & $2.57(0.86-5.14)$ & 20 \\
\hline Polypill scenario 2C & $29.7(10.5-52.4) \mathrm{k}$ & $3.60(1.30-6.34)$ & 25 & $47.4(16.4-95.0) \mathrm{k}$ & $3.37(1.17-6.78)$ & 15 \\
\hline
\end{tabular}

The main effect of choosing a different cut-point is that the ICERs for the polypill scenarios decrease with lower SCORE thresholds. Opportunistic screening combined with the polypill without aspirin and doubling of the statin doses (scenario 2C) had the most favourable ICER with a SCORE threshold of $5 \%$. For the other thresholds, separate medication has the lowest ICER. It must be noted, though, that the total health gain in the separate medication scenario is only about $1 / 3$ to $1 / 2$ of the total health gain of scenario $2 \mathrm{C}$. We also performed separate analyses by gender and age (table 6). For all scenarios, the costs per QALY were higher for women than for men in all age categories but remained far below the threshold of $€ 20000$.

Figure 2 displays the range of values for costs and effects (QALYs) in the cost-effectiveness plane for $7.5 \%$ risk. It shows that most values cluster narrowly along what can be imagined as a line, which has a slope in the average cost-effectiveness ratio.

Figure 3 shows acceptability curves for the choice of treatment strategy for $7.5 \%$ risk. For each cost-effectiveness threshold (the maximum value below which a treatment is accepted as being cost-effective or the 'willingness to pay'), it gives the probability that the treatment will be cost-effective. Thus, up to a level of about $€ 9000 /$ QALY, separate medication is most likely to be cost-effective but beyond that scenario $2 \mathrm{C}$ is most likely the best alternative.

Variation of the costs of the most cost-effective polypill (scenario 2C) showed that when the price of the pill would be under $€ 50$ per year (excluding drug delivery costs and including VAT), scenario 2C would become the most favourable scenario when using a SCORE threshold of $7.5 \%$. In the present calculations, we estimated the price of the polypill in scenario $2 \mathrm{C}$ to be $€ 65.76$ per year.

\section{Probabilistic sensitivity analysis}

Results of the sensitivity analysis are displayed in table 7 as $95 \%$ CIs for the outcomes measures, meaning that $95 \%$ of the simulations fell within the indicated ranges. It can be observed that the ICERs are within a rather small range. In that respect, results can be judged to be robust. Nonetheless, there is some overlap between intervals, meaning that the relative order of the different medication compositions could be different. Table 8 shows the results of the analyses of the base case scenario with different discount rates.

\section{DISCUSSION}

The results of this study suggest that opportunistic screening and offering a polypill to people with a minimum 10-year risk of cardiovascular mortality of

Table 5 Outcomes and ICERs (total costs per LY and QALY gained) compared with current practice

\begin{tabular}{|c|c|c|c|c|c|c|c|c|c|c|c|c|}
\hline \multirow{2}{*}{$\frac{\text { Outcomes }}{\text { Risk threshold }}$} & \multicolumn{3}{|c|}{ Polypill scenario 2A } & \multicolumn{3}{|c|}{ Polypill scenario 2B } & \multicolumn{3}{|c|}{ Polypill scenario 2C } & \multicolumn{3}{|c|}{$\begin{array}{l}\text { Separate medication } \\
\text { scenario } 3\end{array}$} \\
\hline & $5 \%$ & $7.5 \%$ & $10 \%$ & $5 \%$ & $7.5 \%$ & $10 \%$ & $5 \%$ & $7.5 \%$ & $10 \%$ & $5 \%$ & $7.5 \%$ & $10 \%$ \\
\hline $\begin{array}{l}\text { Cost of intervention } \\
\left(\times 10^{6} €\right)\end{array}$ & 954 & 907 & 870 & 921 & 876 & 840 & 967 & 914 & 872 & 331 & 319 & 309 \\
\hline $\begin{array}{l}\text { Incremental healthcare } \\
\text { costs }\left(\times 10^{6} €\right)\end{array}$ & 2210 & 1710 & 1320 & 1940 & 1500 & 1160 & 2240 & 1730 & 1330 & 750 & 720 & 690 \\
\hline $\begin{array}{l}\text { Total incremental } \\
\text { costs }\left(\times 10^{6} €\right)\end{array}$ & 3390 & 2830 & 2400 & 2860 & 2370 & 2000 & 3210 & 2640 & 2200 & 1080 & 1040 & 999 \\
\hline LYs gained $\left(\times 10^{3}\right)$ & 425 & 314 & 236 & 395 & 291 & 218 & 474 & 349 & 261 & 154 & 147 & 141 \\
\hline QALYs gained $\left(\times 10^{3}\right)$ & 360 & 266 & 195 & 335 & 244 & 182 & 408 & 296 & 221 & 132 & 126 & 122 \\
\hline $\operatorname{ICER}\left(\times 10^{3} \in / L Y\right)$ & 8.0 & 9.0 & 10.2 & 7.2 & 8.2 & 9.1 & 6.8 & 7.6 & 8.5 & 7.0 & 7.0 & 7.1 \\
\hline ICER $\left(\times 10^{3} \in / Q A L Y\right)$ & 9.4 & 10.8 & 12.3 & 8.5 & 9.7 & 10.9 & 7.9 & 8.9 & 10.0 & 8.2 & 8.2 & 8.2 \\
\hline
\end{tabular}


Table 6 Outcomes and ICERs compared with current practice

\begin{tabular}{|c|c|c|c|c|c|c|c|c|c|c|c|c|c|c|c|c|c|}
\hline \multirow[t]{2}{*}{ Outcomes } & \multirow[b]{2}{*}{ Sexlage } & \multicolumn{4}{|c|}{ Polypill scenario 2A } & \multicolumn{4}{|c|}{ Polypill scenario 2B } & \multicolumn{4}{|c|}{ Polypill scenario $2 \mathrm{C}$} & \multicolumn{4}{|c|}{$\begin{array}{l}\text { Separate medication } \\
\text { scenario } 3\end{array}$} \\
\hline & & $\begin{array}{l}40- \\
49\end{array}$ & $\begin{array}{l}50- \\
59\end{array}$ & $\begin{array}{l}60- \\
69\end{array}$ & $\begin{array}{l}70- \\
75\end{array}$ & $\begin{array}{l}40- \\
49\end{array}$ & $\begin{array}{l}50- \\
59\end{array}$ & $\begin{array}{l}60- \\
69\end{array}$ & $\begin{array}{l}70- \\
75\end{array}$ & $\begin{array}{l}40- \\
49\end{array}$ & $\begin{array}{l}50- \\
59\end{array}$ & $\begin{array}{l}60- \\
69\end{array}$ & $\begin{array}{l}70- \\
75\end{array}$ & $\begin{array}{l}40- \\
49\end{array}$ & $\begin{array}{l}50- \\
59\end{array}$ & $\begin{array}{l}60- \\
69\end{array}$ & $\begin{array}{l}70- \\
75\end{array}$ \\
\hline ICER $\left(\times 10^{3}\right.$ & Men & 6.9 & 7.8 & 8.3 & 11.4 & 6.0 & 6.8 & 7.4 & 10.3 & 5.3 & 5.9 & 6.7 & 9.6 & 4.2 & 4.4 & 6.0 & 9.6 \\
\hline$€ / Q A L Y)$ & Women & NA & 8.9 & 13.9 & 17.2 & NA & 8.7 & 13.7 & 16.7 & NA & 8.4 & 12.6 & 15.8 & NA & 8.7 & 11.0 & 14.8 \\
\hline
\end{tabular}

between $5 \%$ and $10 \%$ is a cost-effective strategy in the primary prevention of CVDs. This is the case, whether the threshold chosen is $5 \%, 7.5 \%$ or $10 \%$, but the lower the threshold, the lower the incremental cost-effectiveness ratio. All three differently composed polypills were cost-effective compared with usual care, as was the single drug option. The polypill without aspirin but with a double dose of simvastatin leads to most health gains with all risk thresholds. At a 10-year risk of cardiovascular death of $\geq 7.5 \%$, such a strategy would lead to an estimated decrease in the incidence of myocardial infarction and stroke of about $3.5 \%$, at a cost of $€ 8900$ per QALY. This is well below the consensual threshold of $€ 20000$ per QALY. $^{40}$ Separate medication, targeted at hypertension and/or hypercholesterolaemia, is the most cost-effective strategy compared with usual care in the risk classes of $7.5 \%$, respectively $10 \%$, or above. However, total health gains are substantially lower.

Both the strengths and weaknesses of our study revolve around the weak basis of clinical evidence and the use of mathematical modelling. The latter allowed an exploratory investigation based on preliminary results of a phase II clinical trial, thus providing insights into the range of health benefits that can be expected. But with the lack of evidence of efficacy with regard to established clinical endpoints, the results should certainly not be taken as a precise estimate of the cost-effectiveness. We took into account what seemed to be the most important factors determining cost-effectiveness.

Since Wald and Law's 2003 article, the appealing idea of a highly effective and safe polypill taken once daily to

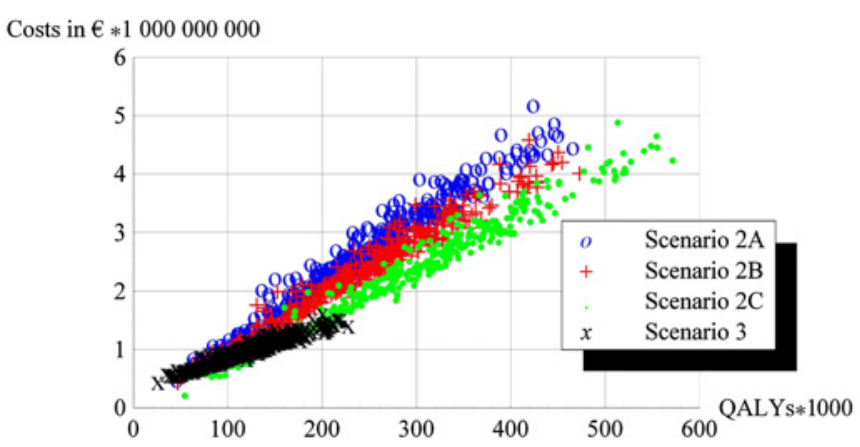

Figure 2 Cost-effectiveness plane: scatter plot of costs and quality adjusted life years (QALYs). prevent CVD has gained widespread attention. Soon, the question of cost-effectiveness was raised. Thus, Franco and colleagues developed a model to estimate the maximum price of the polypill for it still to be costeffective in the primary prevention of CVD. ${ }^{41}$ As input, they used the hypothetical effectiveness estimates from Wald and Law's article and applied them to a population with the characteristics of the Framingham and Framingham offspring study cohort. This population was classified into three classes according to 10-year coronary heart disease risk using a risk score (the Anderson equation). Costs were calculated on the basis of unit costs valid for the healthcare system in the Netherlands. The calculations showed that the pill would be costeffective (<€20000 per year of life saved) as long as the yearly costs of the pill would be below approximately $€ 270$ in high-risk groups and $€ 160$ in intermediate-risk groups $(10 \%-20 \%$ risk). Indeed, with the yearly costs of the polypill we assumed in our study, which were far below this threshold, we found all scenarios to be costeffective. This was despite the fact that the effectiveness estimates we used were much lower than those of Wald and Law's.

These lower estimates are due to insights gained since then, as steps towards realisation of the polypill concept have been taken. Several prototypes have been developed and large-scale clinical trials are currently under way. Yet, the only clinical evidence so far concerns a brief randomised trial of 12 weeks of treatment, the Polycap Study. On the basis of this limited evidence, it was concluded that the pill seems safe and that the effects on

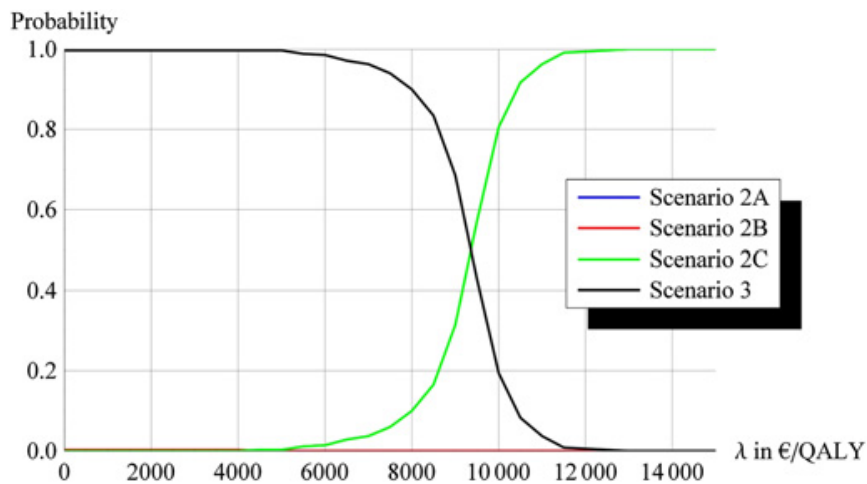

Figure 3 Acceptability curves for the choice of treatment strategy. 
Table 7 Results of the probabilistic sensitivity analysis

\begin{tabular}{|c|c|c|c|c|}
\hline Outcomes & Polypill scenario 2A & Polypill scenario 2B & Polypill scenario $2 \mathrm{C}$ & Separate medication \\
\hline Cost of intervention $\left(\times 10^{6} €\right)$ & 380 to 1510 & 370 to 1460 & 380 to 1540 & 290 to 360 \\
\hline $\begin{array}{l}\text { Incremental healthcare costs } \\
\left(\times 10^{6} €\right)\end{array}$ & 580 to 2630 & 560 to 2570 & 640 to 2980 & 290 to 1140 \\
\hline $\begin{array}{l}\text { Total incremental costs } \\
\left(\times 10^{6} €\right)\end{array}$ & 1070 to 4450 & 940 to 4000 & 1040 to 4490 & 610 to 1460 \\
\hline LYs gained $\left(\times 10^{3}\right)$ & 113 to 517 & 110 to 507 & 130 to 613 & 59 to 241 \\
\hline QALYs gained $\left(\times 10^{3}\right)$ & 92 to 424 & 92 to 427 & 109 to 519 & 50 to 206 \\
\hline $\operatorname{ICER}\left(\times 10^{3} \in / L Y\right)$ & 8.2 to 10.7 & 7.4 to 9.8 & 6.9 to 9.0 & 5.9 to 10.8 \\
\hline $\operatorname{ICER}\left(\times 10^{3} \in / \mathrm{QALY}\right)$ & 9.9 to 13.0 & 8.8 to 11.7 & 8.1 to 10.7 & 6.9 to 12.6 \\
\hline
\end{tabular}

blood pressure and cholesterol are not inferior to the individual substances given separately. However, it must be said that the effects on these intermediate endpoints fall well below the rough estimates made by Law and Wald, who calculated that up to $80 \%$ of all cardiovascular events in the population at large could be prevented. There are two main sources for the discrepancy between their estimates and our calculations. First, both the estimated effects on intermediate endpoints and the RR reductions (per unit of risk factor level reduction) Law and Wald used seem to have been too optimistic. Second, we did not consider the introduction of the polypill in the 'universal' manner envisioned in their original article. It seems very unlikely that medicalisation of a whole population will ever find wide support. Instead, we imagined a situation in which the polypill would be introduced within the current context of cardiovascular risk management and primary prevention. This approach is in line with current views on focusing on those at increased risk and finding ways of identifying them. ${ }^{42}$ Only limited experience exists with this type of primary prevention, which might be best described as opportunistic screening. ${ }^{43}$ Hence, we had to make several assumptions to estimate the number of individuals who would ultimately take the polypill. These include the preparedness of GPs to engage in opportunistic screening, the proportion of eligible individuals who are willing to choose lifelong medication and their compliance with treatment. Many will probably prefer changing their lifestyles or will start but not continue. A

\begin{tabular}{|c|c|c|c|c|}
\hline $\begin{array}{l}\text { Discount } \\
\text { rates: } \\
\text { costs, } \\
\text { effects }\end{array}$ & $\begin{array}{l}\text { Polypill } \\
\text { scenario } \\
2 A\end{array}$ & $\begin{array}{l}\text { Polypill } \\
\text { scenario } \\
\text { 2B }\end{array}$ & $\begin{array}{l}\text { Polypill } \\
\text { scenario } \\
\text { 2C }\end{array}$ & $\begin{array}{l}\text { Separate } \\
\text { medication } \\
\text { scenario } 3\end{array}$ \\
\hline $4 \%, 1.5 \%$ & 10800 & 9700 & 8900 & 8200 \\
\hline $0 \%, 0 \%$ & 17300 & 16200 & 15100 & 14200 \\
\hline $3 \%, 3 \%$ & 16400 & 14900 & 13700 & 12600 \\
\hline $5 \%, 5 \%$ & 16200 & 14200 & 12900 & 11800 \\
\hline
\end{tabular}

lack of compliance obviously reduces cost-effectiveness, as investments are made that do not pay out in terms of health gains. On the other hand, the combination of drugs in one pill takes away an obstacle to compliance in patients requiring more than one drug. ${ }^{44-46} 47$ Literature shows that adherence to medication declines with the number of drugs prescribed. ${ }^{44} 4849$

Especially in primary prevention, the safety and side effects of a drug are of crucial concern. As far as statins are concerned, the most serious complication is rhabdomyolysis, which is very rare, but can be fatal. More frequent are complaints of muscle pain. ${ }^{50}$ However, a review and meta-analysis of Weng et $a l^{34}$ of 75 trials showed that the incidence of muscle toxicity was low in all trials. The most recent Cochrane meta-analysis did not find significant differences between placebo and treatment groups. The most important consequence would be that the relatively minor side effects would reduce adherence or lead to discontinuation, an effect that is indirectly included in our model (via reduced compliance). The same applies to the side effects of the blood pressure-lowering components. In particular, cough caused by an ACE inhibitor, which is independent of the dose, could lead to discontinuation of the pill. ${ }^{28}$ Aspirin can cause gastrointestinal bleedings and hemorrhagic stroke. ${ }^{38} 5152$ The latter more or less annul the protective effect on ischaemic stroke, such that the net effect is neutral. The increased risk of gastrointestinal bleeding, which we took into account, further contributed to the relatively unfavourable profile of a polypill containing aspirin, which turned out to be the least cost-effective option.

To gain more definite insights into the cost-effectiveness of the polypill in the opportunistic screening setting, two major 'unknowns' need to be clarified. First, the results of large-scale phase III clinical trials will have to show how the effects on intermediate endpoints translate into clinical benefit. In particular, they will need to answer the question whether the 'sum is greater than the parts', both with regard to benefits as to safety. Second, more needs to be known about the willingness to participate in opportunistic screening initiatives. This applies to eligible persons and to GPs. Also the practical 
consequences and logistic difficulties in implementing opportunistic screening will need to be addressed.

\section{Implications}

Primary prevention is increasingly seen as a crucial tool in further reducing the burden of CVD. In a healthcare system such as that of the Netherlands, in which the GP occupies a central role, opportunistic screening is a feasible strategy of which the benefits are currently being actively explored. Thus, in the Netherlands opportunistic screening for cardiovascular disease by the GPs has recently been introduced and reimbursement has been recommended. Obviously, in order to make most out of this opportunity, insights into the relative cost-effectiveness of alternative preventive measures for those at increased risk is essential, as are the implications on effects and costs over a long time. Low doses of aspirin are not recommended in the Dutch guideline in the primary prevention of CVDs. ${ }^{18}$ This is based on the adverse effects like gastrointestinal bleedings and hemorrhagic stroke caused by aspirin. ${ }^{51} 52$ The advantage of using a polypill without aspirin is that these adverse effects due to aspirin could be avoided.

Since the introduction of the concept of a polypill by Wald and Law, there were different changes in the composition and dosage of the medication put into this pill. One can expect that in the future further changes in the composition and dosage will lead to a betterbalanced pill. For example, ACE antihypertensive drugs often cause an unpleasant tickling cough. Replacement with a selective type 1 angiotensin II-receptor $\left(\mathrm{AT}_{1}\right)$ antagonist could solve this problem.

Guidelines on primary prevention cardiovascular suggest first to start with lifestyle changes such as increasing physical activity and diet advices. In our calculations, we did not include the costs and the effects of a lifestyle advisor.

\section{Conclusions}

The polypill or variants thereof seem to offer an efficient way to reduce the CVD burden. Opportunistic screening of the population of $\geq 40$ years to select individuals with a mild to moderately increased risk for CVDs, followed by polypill prescription, would prevent approximately $3.5 \%$ of all cardiovascular events. The cost-effectiveness of all variants is within the same order of magnitude. Therefore, other aspects will determine which composition of pill is to be preferred, such as side effect profile and total health gains. Based on these criteria, our study suggests that the polypill without aspirin and a double statin dose is the most favourable option.

Funding This research received no specific grant from any funding agency in the public, commercial or not-for-profit sectors.

\section{Competing interests None.}

Contributors PFvG: study design, data analyses and writing; EABO: study design, statistics and data analyses; HHHvR: study design and writing; GAdW: study design and writing; MvdB: writing; AJS: writing; PME: study design and data analyses, writing. All authors reviewed the manuscript and critically analysed the work.

Provenance and peer review Not commissioned; externally peer reviewed.

Data sharing statement We invite any reader who is interested in seeing the input data and the software code of our model to contact us. We offer full access to both the data used and the code. The data are available in the Dryad repository with the unique identifier: doi:10.5061/dryad.qg54c627.

\section{REFERENCES}

1. Wald NJ, Law MR. A strategy to reduce cardiovascular disease by more than $80 \%$. BMJ 2003;326:1419.

2. AHA. Cardiovascular Disease Statistics. Dallas, Texas, USA: American Heart Association, 2010.

3. CBS. Causes of Death 2009, Short List. The Hague, the Netherlands: CBS, 2010.

4. Vaartjes I, van Dis I, Visseren FLJ, et al. Chapter 1: Cardiovascular Disease in the Netherlands (in Dutch). Cardiovascular Diseases in the Netherlands, 2009. Den Haag, The Netherlands: Dutch Heartfoundation, 2009.

5. Zhao G, Ford ES, Li C, et al. Are United States adults with coronary heart disease meeting physical activity recommendations? $A m \mathrm{~J}$ Cardiol 2008;101:557-61.

6. Garner JB. Problems of nonadherence in cardiology and proposals to improve outcomes. Am J Cardiol 2010;105:1495-501.

7. Bates TR, Connaughton VM, Watts GF. Non-adherence to statin therapy: a major challenge for preventive cardiology. Expert Opin Pharmacother 2009;10:2973-85.

8. Corrao G, Conti V, Merlino L, et al. Results of a retrospective database analysis of adherence to statin therapy and risk of nonfata ischemic heart disease in daily clinical practice in Italy. Clin Ther 2010;32:300-10.

9. Graham I, Atar D, Borch-Johnsen K, et al. European guidelines on cardiovascular disease prevention in clinical practice: executive summary. Fourth Joint Task Force of the European Society of Cardiology and other societies on cardiovascular disease prevention in clinical practice (constituted by representatives of nine societies and by invited experts). Eur J Cardiovasc Prev Rehabil 2007;14 (Suppl 2):E1-40.

10. Conroy RM, Pyorala K, Fitzgerald AP, et al. Estimation of ten-year risk of fatal cardiovascular disease in Europe: the SCORE project. Eur Heart J 2003;24:987-1003.

11. Lonn E, Bosch J, Teo KK, et al. The polypill in the prevention of cardiovascular diseases: key concepts, current status, challenges, and future directions. Circulation 2010;122:2078-88.

12. Yusuf $S$, Pais $P$, Afzal R, et al. Effects of a polypill (polycap) on risk factors in middle-aged individuals without cardiovascular disease (TIPS): a phase II, double-blind, randomised trial. Lancet 2009;373:1341-51.

13. Lonn E, Yusuf S, Arnold MJ, et al. Homocysteine lowering with folic acid and B vitamins in vascular disease. $N$ Engl $J$ Med 2006;354:1567-77.

14. van Dis I, Kromhout D, Geleijnse JM, et al. Evaluation of cardiovascular risk predicted by different SCORE equations: the Netherlands as an example. Eur J Cardiovasc Prev Rehabil 2010;17:244-9.

15. Hoogenveen RT, van Baal PH, Boshuizen HC. Chronic disease projections in heterogeneous ageing populations: approximating multi-state models of joint distributions by modelling marginal distributions. Math Med Biol 2010;27:1-19.

16. Jacobs-van der Bruggen MA, Bos G, Bemelmans WJ, et al. Lifestyle interventions are cost-effective in people with different levels of diabetes risk: results from a modeling study. Diabetes Care 2007;30:128-34.

17. De Backer G, Ambrosioni E, Borch-Johnsen K, et al. European guidelines on cardiovascular disease prevention in clinical practice. Third Joint Task Force of European and Other Societies on Cardiovascular Disease Prevention in Clinical Practice. Eur Heart $J$ 2003;24:1601-10.

18. CBO. Dutch Guideline Cardiovascular Risk Management. In: CBO DIfHI, ed. Utrecht, The Netherlands: Dutch Institute for Healthcare Improvement CBO, 2006.

19. Baal PHM, Feenstra TL, Hoogenveen RT, et al. Cost-Efectiveness analysis with the RIVM Chronic Disease Model. Bilthoven, Netherlands: Dutch National Institute for Public Health and the Environment, 2005

20. Slobbe LCJ, Kommer GJ, Smit JM, et al. Cost-of-illness in the Netherlands 2003. Bilthoven, Netherlands: National Institute for Public Health and the Environment, 2006. 
21. Melse JM, Essink-Bot ML, Kramers PG, et al. A national burden of disease calculation: Dutch disability-adjusted life-years. Dutch Burden of Disease Group. Am J Public Health 2000;90:1241-7.

22. Stouthard MEA, Essink-Bot ML, Bonsel GJ. Disability weights for diseases: a modified protocol and results for a Western European region. Eur J Public Health 2000;10:24-30.

23. Lopez AD, Murray CC. The global burden of disease, 1990-2020. Nat Med 1998;4:1241-3.

24. van Baal PH, Hoeymans N, Hoogenveen RT, et al. Disability weights for comorbidity and their influence on health-adjusted life expectancy. Popul Health Metr 2006;4:1.

25. Verschuren WM, Blokstra A, Picavet HS, et al. Cohort profile: the Doetinchem Cohort Study. Int J Epidemiol 2008;37:1236-41.

26. CBS. Statistics Netherlands. The Hague, the Netherlands: CBS, 2010.

27. Chapman RH, Petrilla AA, Benner JS, et al. Predictors of adherence to concomitant antihypertensive and lipid-lowering medications in older adults: a retrospective, cohort study. Drugs Aging 2008;25:885-92.

28. Law MR, Wald NJ, Morris JK, et al. Value of low dose combination treatment with blood pressure lowering drugs: analysis of 354 randomised trials. BMJ 2003;326:1427.

29. Turnbull F, Neal B, Ninomiya T, et al. Effects of different regimens to lower blood pressure on major cardiovascular events in older and younger adults: meta-analysis of randomised trials. $\mathrm{Bmj}$ 2008;336:1121-3.

30. Turnbull F, Neal B, Algert C, et al. Effects of different blood pressurelowering regimens on major cardiovascular events in individuals with and without diabetes mellitus: results of prospectively designed overviews of randomized trials. Arch Intern Med 2005;165:1410-19.

31. Taylor F, Ward K, Moore TH, et al. Statins for the primary prevention of cardiovascular disease. Cochrane Database Syst Rev 2011;(1): CD004816.

32. Baigent $\mathrm{C}$, Blackwell L, Emberson J, et al. Efficacy and safety of more intensive lowering of LDL cholesterol: a meta-analysis of data from 170,000 participants in 26 randomised trials. Lancet 2010;376:1670-81.

33. Baigent C, Keech A, Kearney PM, et al. Efficacy and safety of cholesterol-lowering treatment: prospective meta-analysis of data from 90,056 participants in 14 randomised trials of statins. Lancet 2005;366:1267-78.

34. Weng TC, Yang YH, Lin SJ, et al. A systematic review and metaanalysis on the therapeutic equivalence of statins. J Clin Pharm Ther 2010;35:139-51.

35. Baigent $\mathrm{C}$, Blackwell $\mathrm{L}$, Collins $\mathrm{R}$, et al. Aspirin in the primary and secondary prevention of vascular disease: collaborative metaanalysis of individual participant data from randomised trials. Lancet 2009;373:1849-60.

36. Hakkaart-van Roijen L, Tan SS, Bouwmans CAM. Manual for Costing Research. Methods and Directive Prices For Economic Evaluation In
Health Care (In Dutch). Diemen: Institute for Medical Technology Assessment. Erasmus MC, 2010.

37. CVZ. Medicijnkosten. Diemen: CVZ, 2010.

38. Berger JS, Roncaglioni MC, Avanzini F, et al. Aspirin for the primary prevention of cardiovascular events in women and men: a sexspecific meta-analysis of randomized controlled trials. JAMA 2006;295:306-13.

39. Pignone M, Earnshaw S, Pletcher MJ, et al. Aspirin for the primary prevention of cardiovascular disease in women: a cost-utility analysis. Arch Intern Med 2007;167:290-5.

40. van den Berg M, de Wit GA, Vijgen SM, et al. [Cost-effectiveness of prevention: opportunities for public health policy in the Netherlands] (In Dutch). Ned Tijdschr Geneeskd 2008;152:1329-34.

41. Franco $\mathrm{OH}$, Steyerberg $\mathrm{EW}$, de Laet $\mathrm{C}$. The polypill: at what price would it become cost effective? J Epidemiol Community Health 2006;60:213-17.

42. Wald NJ, Simmonds M, Morris JK. Screening for future cardiovascular disease using age alone compared with multiple risk factors and age. PLoS One 2011;6:e18742.

43. van de Kerkhof RM, Godefrooij MB, Wouda PJ, et al. [Cardiometabolic risk factors detected with a preventative screening programme] (In Dutch). Ned Tijdschr Geneeskd 2010;154:A1860.

44. Saini SD, Schoenfeld P, Kaulback K, et al. Effect of medication dosing frequency on adherence in chronic diseases. Am J Manag Care 2009;15:e22-33.

45. Pan F, Chernew ME, Fendrick AM. Impact of fixed-dose combination drugs on adherence to prescription medications. J Gen Intern Med 2008;23:611-14.

46. Gerbino PP, Shoheiber O. Adherence patterns among patients treated with fixed-dose combination versus separate antihypertensive agents. Am J Health Syst Pharm 2007;64:1279-83.

47. Erdine S. Compliance with the treatment of hypertension: the potential of combination therapy. J Clin Hypertens (Greenwich) 2010;12:40-6.

48. WHO. Adherence To Long-Term Therapies: Evidence For Action. Geneva, Switzerland: World Health Organization, 2003.

49. Claxton AJ, Cramer J, Pierce C. A systematic review of the associations between dose regimens and medication compliance. Clin Ther 2001;23:1296-310.

50. Pasternak RC, Smith SC Jr, Bairey-Merz CN, et al. ACC/AHA/NHLB clinical advisory on the use and safety of statins. Circulation 2002;106:1024-8.

51. Sanmuganathan PS, Ghahramani P, Jackson PR, et al. Aspirin for primary prevention of coronary heart disease: safety and absolute benefit related to coronary risk derived from meta-analysis of randomised trials. Heart 2001;85:265-71.

52. Hayden M, Pignone M, Phillips $\mathrm{C}$, et al. Aspirin for the primary prevention of cardiovascular events: a summary of the evidence for the U.S. Preventive Services Task Force. Ann Intern Med 2002;136:161-72. 